\title{
Commentary: The Relationship of Bilingualism Compared to Monolingualism to the Risk of Cognitive Decline or Dementia: A Systematic Review and Meta-Analysis
}

\author{
John G. Grundy ${ }^{\star \dagger}$ and John A. E. Anderson ${ }^{\dagger}$ \\ Department of Psychology, York University, Toronto, ON, Canada
}

Keywords: bilingualism, dementia, meta-analysis, cognitive reserve, Alzheimer disease

\section{A commentary on}

The Relationship of Bilingualism Compared to Monolingualism to the Risk of Cognitive Decline or Dementia: A Systematic Review and Meta-Analysis

by Mukadam, N., Sommerlad, A., and Livingston, G. (2017). J. Alzheimer's Dis. 58, 45-54. doi: 10.3233/JAD-170131

OPEN ACCESS

Edited by:

Ashok Kumar,

University of Florida, United States

Reviewed by:

W. Quin Yow,

Singapore University of Technology and Design, Singapore

*Correspondence:

John G. Grundy

jggrundy@gmail.com

${ }^{\dagger}$ These authors have contributed equally to this work.

Received: 10 May 2017 Accepted: 13 October 2017 Published: 25 October 2017

Citation:

Grundy JG and Anderson JAE (2017)

Commentary: The Relationship of

Bilingualism Compared to

Monolingualism to the Risk of

Cognitive Decline or Dementia: A Systematic Review and Meta-Analysis.

Front. Aging Neurosci. 9:344.

doi: 10.3389/fnagi.2017.00344
Evidence suggests that lifelong bilingualism reshapes the brain and helps to prevent cognitive decline in older age (e.g., Bialystok, 2017). For example, Klein et al. (2016) showed bilingual countries have lower incidence rates of dementia than monolingual countries. Mukadam et al. (2017) conducted a meta-analysis examining the strength of the protective effect of bilingualism on dementia. The authors claim retrospective studies are often confounded by extraneous variables, whereas prospective studies are less susceptible. They conducted a meta-analysis and concluded that bilingualism does not protect from dementia given that only retrospective studies showed positive effects of bilingualism. However, three factors undermine their analysis and challenge their conclusions.

\section{STATISTICAL ISSUES}

Although the authors state that 13 articles were included in their meta-analysis, the analysis included only four studies (Sanders et al., 2012; Yeung et al., 2014; Zahodne et al., 2014; Lawton et al., 2015), all of which were prospective. Thus, any conclusions comparing retrospective and prospective studies are not supported by statistical evidence. Nonetheless, of the four prospective studies included in the analysis, three included information regarding age at onset, the same measure as the retrospective studies. However, the authors did not analyze these data, arguing that "[t]hese outcomes were too heterogeneous to be combined in a meta-analysis." We respectfully disagree given that meta-analyses are used precisely for the purpose of combining heterogeneous data and examining overall patterns. A more direct comparison of prospective and retrospective studies would be to include both types of studies within the same model using age at onset of dementia. It would have also been possible to include age at onset and incidence rate in a single analysis. One of the key features of a meta-analysis is that the individual studies included do not need to have the same dependent variables (Field and Gillett, 2010). The dependent variables are converted to effect sizes (e.g. Cohen's $d$ ), and it allows comparison of disparate outcomes 
(i.e., incidence/age of onset). Thus, including retrospective and prospective studies in a single meta-analysis would have allowed for the examination of whether the type of study (retrospective vs. prospective) moderated the overall effect. It is possible that such an analysis based on both study types would favor bilinguals and that the moderator analysis would not reveal a difference between the sources, but the analyses that are presented simply allow no conclusions.

\section{CONCEPTUAL ISSUES}

Retrospective and prospective studies have not examined the same outcome variable. Retrospective studies have examined age at onset of dementia symptoms, whereas prospective studies have examined dementia incidence rate. Given that prospective and retrospective studies have not studied the same outcome variable, this likely contributes to bilingualism being protective in one case and not the other-particularly when this relationship is not explicitly modeled with moderator analyses. Retrospective dementia studies often interpret their data according to a cognitive reserve perspective - the individual can cope with more neural degeneration (e.g., Perani et al., 2017). From this standpoint, one should not necessarily expect incidence rates of dementia to differ between monolinguals and bilinguals. Both groups will get the disease (eventually), but bilinguals should be able to withstand more disease pathology than monolinguals before reaching a critical drop-off point (hence the later age of onset for bilinguals). In other words, what is critical is not whether the individual gets the disease, but how quickly he or she accrues symptoms.

\section{METHODOLOGICAL ISSUES}

The authors' claim that retrospective studies are often confounded by extraneous variables to which prospective studies are less susceptible. While this is generally true, methodological flaws are pervasive in the prospective studies included in the analysis outweighing the benefits of the within-subject design. For example, Sanders et al. (2012) failed to ask their "monolinguals" if they spoke or understood other languages, a failing noted by Mukadam et al. Relatedly, Zahodne et al. (2014) failed to report second language proficiency and use and included "bilinguals" that reported speaking their second language "not well". These limitations alone make it difficult to rule out the possibility that some of the monolinguals in these studies were,

\section{REFERENCES}

Alladi, S., Bak, T. H., Duggirala, V., Surampudi, B., Shailaja, M., Shukla, A. K.,., et al. (2013). Bilingualism delays age at onset of dementia, independent of education and immigration status. Neurology 81, 1938-1944. doi: 10.1212/01.wnl.0000436620.33155.a4

Bak, T. H., Nissan, J. J., Allerhand, M. M., and Deary, I. J. (2014). Does bilingualism influence cognitive aging?. Ann. Neurol. 75, 959-963. doi: 10.1002/ana.24158

Bialystok, E. (2017). The bilingual adaptation: how minds accommodate experience. Psychol. Bull. 143, 233-262. doi: 10.1037/bul0000099 in fact, receptive bilinguals, and that some bilinguals were not very proficient in their second languages. It is therefore not entirely surprising that there were no significant differences in these cases. In contrast, many of the retrospective studies carefully controlled for multiple confounding variables, and these studies generally reported positive effects for bilingualism. For example, Craik et al. (2010) controlled for education and gender, as well as cognitive and occupational levels and found that bilinguals showed symptoms of dementia 5.1 years later than monolinguals. Alladi et al. (2013) examined a sample of individuals from an Indian population and revealed a delay of 4.5 years for bilinguals, independent of immigration status and the aforementioned controls.

A second methodological issue relates to Mukadam et al.'s use of the Newcastle-Ottawa scale (Wells et al., 2012). Controlling for quality is standard practice with meta-analyses, but the quality ratings were not consistent. Prospective studies automatically received extra points, increasing their likelihood of inclusion and therefore biasing the results. Retrospective studies were eliminated and in our view, were not fairly considered. Moreover, the interpretation of the quality scores was also inconsistent: the authors claim that a study by Bak et al. (2014), was of "lower quality," yet two of the four studies included in the prospective meta-analysis received the same score.

\section{CONCLUSIONS}

Well-controlled prospective studies would be informative and help uncover the differences between bilingual and monolingual individuals as they progress into Alzheimer's disease. These studies could also help to reveal the mechanisms allowing bilinguals to stave off symptoms for longer. However, such wellcontrolled prospective studies are still lacking. Of the studies that exist and provide adequate control for confounds, most of which are retrospective, bilingualism is generally found to be protective and delays symptoms for about 4.5 years. The overall picture still favors bilingualism protecting against symptoms of dementia. We suggest that the authors' recommendation that bilingualism be removed from consideration as a protective factor by policy makers is premature.

\section{AUTHOR CONTRIBUTIONS}

All authors listed have made a substantial, direct and intellectual contribution to the work, and approved it for publication.

Craik, F. I., Bialystok, E., and Freedman, M. (2010). Delaying the onset of Alzheimer disease Bilingualism as a form of cognitive reserve. Neurology 75, 1726-1729. doi: 10.1212/WNL.0b013e3181fc2a1c

Field, A. P., and Gillett, R. (2010). How to do a meta-analysis. Br. J. Math. Stat. Psychol. 63, 665-694. doi: 10.1348/000711010X502733

Klein, R. M., Christie, J., and Parkvall, M. (2016). Does multilingualism affect the incidence of Alzheimer's disease?: a worldwide analysis by country. SSM-Popul. Health 2, 463-467. doi: 10.1016/j.ssmph.2016.06.002

Lawton, D. M., Gasquoine, P. G., and Weimer, A. A. (2015). Age of dementia diagnosis in community dwelling bilingual and monolingual 
Hispanic Americans. Cortex 66, 141-145. doi: 10.1016/j.cortex.2014. 11.017

Mukadam, N., Sommerlad, A., and Livingston, G. (2017). The relationship of bilingualism compared to monolingualism to the risk of cognitive decline or dementia: a systematic review and meta-analysis. J. Alzheimer's Dis. 58, 45-54. doi: 10.3233/JAD-170131

Perani, D., Farsad, M., Ballarini, T., Lubian, F., Malpetti, M., Fracchetti, A.,., et al. (2017). The impact of bilingualism on brain reserve and metabolic connectivity in Alzheimer's dementia. Proc. Natl. Acad. Sci. U.S.A. 114, 1690-1695. doi: 10.1073/pnas.16109 09114

Sanders, A. E., Hall, C. B., Katz, M. J., and Lipton, R. B. (2012). Non-native language use and risk of incident dementia in the elderly. J. Alzheimer's Dis. 29, 99-108. doi: 10.3233/JAD-2011-111631

Wells, G. A., Shea, B., O'connell, D., Petersen, J., Welch, V., Losos, M., et al. (2012). The Newcastle-Ottawa Scale (NOS) for Assessing the Quality of Nonrandomized Studies in Meta-Analyses. Available online at: http://www.ohri.ca/programs/ clinical_epidemiology/oxford.asp
Yeung, C. M., St John, P. D., Menec, V., and Tyas, S. L. (2014). Is bilingualism associated with a lower risk of dementia in community-living older adults? Cross-sectional and prospective analyses. Alzheimer Dis. Asso. Disord. 28, 326-332. doi: 10.1097/WAD.0000000000000019

Zahodne, L. B., Schofield, P. W., Farrell, M. T., Stern, Y., and Manly, J. J. (2014). Bilingualism does not alter cognitive decline or dementia risk among Spanishspeaking immigrants. Neuropsychology 28: 238. doi: 10.1037/neu0000014

Conflict of Interest Statement: The authors declare that the research was conducted in the absence of any commercial or financial relationships that could be construed as a potential conflict of interest.

Copyright (C) 2017 Grundy and Anderson. This is an open-access article distributed under the terms of the Creative Commons Attribution License (CC BY). The use, distribution or reproduction in other forums is permitted, provided the original author(s) or licensor are credited and that the original publication in this journal is cited, in accordance with accepted academic practice. No use, distribution or reproduction is permitted which does not comply with these terms. 